\title{
Men's Role in Emergency Obstetric Care in Osun State of Nigeria
}

\author{
Clifford Odimegwu ${ }^{1}$, Alfred Adewnyiz, Tanwa Odebiyi $i^{3}$, Bisi Aina ${ }^{4}$, Yinka Adesina ${ }^{5}$, Olu Olatubara ${ }^{6}$ and Femi \\ Eniola
}

\begin{abstract}
This study was conducted among the Yoruba of South-West Nigeria to examine the role of men in emergency obstetric care, as men determine whether and when their spouses visit health clinics in most cultures. Simple random sampling was used to select 900 households from three communities in Osun State, south-west Nigeria. Separate interviewers interviewed the man and his wife in each of the households. In polygamous families, two wives of reproductive age were also interviewed. The quantitative survey was complemented with a number of focus group discussions, in-depth interviews and key informant interviews. There was high level of awareness of emergency obstetric conditions by men, particularly in relation to pregnancy signs and labour pains $(53.2 \%)$. Respondents reported that men play useful roles during their partner's obstetric conditions ( $89.2 \%)$. Women take decisions on health-seeking behaviour during emergency obstetric conditions in the absence of the male partner. Education is found to be the major determinant of this change in male knowledge and behaviour. There is a need to further promote universal basic education in the country especially in areas where the observable change in this study has not been noted. There is also a need to extend the study to other zones in Nigeria in order to have a national picture. (Afr J Reprod Health 2005; 9[3]:59-71)
\end{abstract}

\section{RÉSUMÉ}

Le rôle des hommes par rapport au soin obstétrical d'urgence dans l'état d'Osun au Nigéria Cette étude a été menée au sein des Yorubas du sud-ouest du Nigéria afin d'examiner le rôle des hommes par rapport au soin obstétrical d'urgence puisque ce sont les hommes qui décident si ou non leurs femmes doivent fréquenter les centres de santé dans la plupart des cultures. A l'aide d'un simple échantillon pris au hasard, nous avons selectionné 900 ménages dans trois communautés dans l'état d'Osun au sud-ouest du Nigéria. Dans chacun des ménages, des enquêteurs différents ont intérrogé l'homme et sa femme. Dans les familles polygames, deux femmes en âge d'avoir des enfants ont été également interrogées. Des discussions à groupe cible, des interviews en profondeur et l'interrogation des principaux informateurs ont eu lieu pour compléter l'enquête qualitative. Il y avait un niveau élevé de conscience de la condition obstétricale d'urgence chez les hommes, surtout quand il s'agissait des indications de la grossesse et des douleurs du travail $(53,2 \%)$. Les gens interrogés ont rapporté que les hommes jouent des rôles importants quand leurs partenaires subissent les conditions obstétricales $(89,2 \%)$. Quand les maris ne sont pas présents, les femmes prennent des décisions concernant l'attitude envers les services médicaux au moment des conditions obstétricales d'urgence. On a constaté que l'éducation est le principal déterminant de cette modification de la connaissance et l'attitude chez les hommes. Il est necessaire de promouvoir davantage l'éducation fondamentale universelle dans le pays, surtout dans les domaines où la modification évidente dans cette étude n'a pas été remarquée. Il est également nécessaire de mener l'étude dans d'autres zones au Nigéria. (Rev Afr Santé Reprod 2005; 9[3]:59-71)

Key Words: Cultures, Polygamous families, Emergency, Male

${ }^{1}$ Schools of Public Health and Social Sciences, University of the Witwatersrand, Johannesburg, South Africa. ${ }^{2}$ Professor of Demography and Social Statistics, Obafemi Awolowo University, Ile-Ife, Nigeria and Executive Director of the Centre for Evaluation, Research and Development, Ede, Osun State. ${ }^{3}$ Professor of Medical Sociology, Obafemi Awolowo University, Ile-Ife, Nigeria. ${ }^{4}$ Professor of Industrial and Medical Sociology. ${ }^{5}$ Professor of Geography, Obafemi Awolowo University, Ile-Ife, Nigeria. ${ }^{6}$ Urban Studies expert, University of Ibadan, Nigeria. ${ }^{7}$ Consultant Obstetrician and Gynecologist, Obafemi Awolowo University Teaching Hospital, Ile-Ife, Nigeria.

Correspondence: Clifford Odimegwu, Schools of Public Health and Social Sciences, University of the Witwatersrand, Johannesburg, South_Africa.E-mail: odimegwuc@social.wits.ac.za 
60 African Journal of Reproductive Health

\section{Introduction}

Maternal mortality and morbidity rates in Nigeria have remained among the highest in the world today. UNFPA estimates that the current maternal mortality rate in Nigeria is between 800 and 1,500 deaths per 100,000 live births. ${ }^{1,2}$ The risk of dying during pregnancy or childbirth faced by Nigerian women is 100 times greater than that faced by women in the developed countries. More Nigerian women are known to suffer serious and often permanent damage to their health. ${ }^{1,3-7}$ The major causes of these deaths include postpartum haemorrhage, obstructed labour, hypertension, postpartum infection and abortion-related complications. ${ }^{3-7}$ The Safe Motherhood Initiative helped to draw international attention to the problem of maternal mortality in developing countries. However, many studies still continue to show that existing strategies to save mothers' lives have been less successful than child survival programmes. ${ }^{3-7}$

To prevent maternal mortality and morbidity, interventions have been in the area of hospital care. Less emphasis is placed on the adverse maternal outcomes inextricably tied to social factors that surround decision-making ${ }^{8}$ when emergency obstetric care becomes necessary. This may include recognition of the obstetric condition itself as an emergency, men's granting of permission to their wives to go to the clinic when they are experiencing some discomfort, the expression of concern and determination to take re-assuring action for treatment in the modern health-care facility, etc. In fact, in the few cases where attention is drawn to a cluster of social factors as inhibiting women's reproductive health status, such attention is drawn mainly to the woman's lack of schooling, the early age at marriage and the high frequency at which she bears children, and her difficulties in gaining access to material resources. ${ }^{9}$

The gender ideology as it affects women's reproductive health is often tangentially focused in most studies. Men's role in the family and particularly in the traditional African setting is currently recognised as an important issue to study. ${ }^{10}$ Studies on male role have been on family planning, sexuality and fertility, ${ }^{11,12}$ which concluded that in patriarchal traditional system, men occupy a superior position in the family decision-making processes.

The cultural setting recognises men as the dominant factor in this regard: the man is the head of the family. Even when he is not the primary breadwinner in the household, culture confers on him the final say on family issues. When it comes to reproductive health, men's impression has been that pregnancy is not a sickness and should not necessarily demand the same attention required for a sick person. It is, to many men, ridiculous for women to complain of agonising discomfort in pregnancy. This means the ignorance surrounding pregnancy and childbirth is well recognised in Nigeria; however, the magnitude or level of this ignorance is not known.

Studies have examined men's role in specific reproductive health outcomes. ${ }^{7,13,14}$ Stock comments on the reluctance of husbands to grant their wives permission to go to the health centres, particularly if the journey involves some distance to the health unit, if the condition is not perceived to be threatening, or if she has to go unaccompanied. ${ }^{13,14}$

In a Latin American survey, Robey, et. al. report that young males claimed that they knew little about contraception because they thought this was the girl's responsibility. ${ }^{15}$ Additionally, studies in many parts of the world have reported men as having more sexual partners than women over their lifetime. In the United States, it has been found that $56 \%$ of adult men surveyed said they had five or more partners since the age of 18 , as opposed to $30 \%$ of the women. The median number for men was six and two for women over a lifetime. ${ }^{16}$

In Nigeria, the situation of women is worsened by the fact that there are some traditional norms that tend to sanction men's

African Journal of Reproductive Health Vol. 9 No.3 December 2005 
behaviour and to make women more sexually submissive and less assertive (stigma or divorce, total submission to husband who is the head of the family, etc.). Consequently, women cannot determine when to have sex, and the only periods they are allowed to refuse sex is during menstruation, late pregnancy and postpartum breastfeeding. ${ }^{17,18}$ According to de Zalduondo, et. al., fears of the social consequences (being beaten, divorced/abandoned, neglected, etc.) tend to take priority over the fears of the health consequences of such ill-timed sexual acts. ${ }^{1}$

The tension between husbands and wives with regard to emergency obstetric care is the primary focus of this study, particularly the tension created by specific gender ideology, which emphasises male authority and male choice even in matters of life and death as it relates to the wife. The culture of male superiority and authority over the wife's reproductive rights has implications for women's total wellbeing. ${ }^{10,20-23}$ In northern $\mathrm{Ni}$ geria, Harrison and John note the reluctance of men to grant permission for operative delivery when their wives are in prolonged labour. This is because they perceive this as a sign of reproductive failure, and such actions have been known to have fatal consequences. ${ }^{1,2}$

The practical interpretation of gender ideology for obstetric care is not well known. For example, what transpires in the reproductive decision-making process is not clear, particularly as it relates to men's knowledge of women's health. It is assumed that men's treatment of women's health, especially in the area of emergency obstetric care, may largely depend on the dominant cultural view of pregnancy and its outcomes, rather than a medical understanding of the risk factors associated with pregnancy and its outcomes.

Our literature review did not yield any information relating to male role in emergency obstetric care especially within a cultural context of male supremacy, and the cultural system that views pregnancy and its outcomes as mere routines, rather than risky undertaking. For example, what is the context within which men explain and react to pregnancy related health problems such as haemorrhage, abortion, hypertension, infection and obstructed labour?

Therefore, this study was designed to examine the level of awareness and involvement of male spouses in emergency obstetric conditions of their partners. What do men know about emergency obstetric conditions and care of their wives? To what extent are they involved in the health-seeking behaviour of their spouses during obstetric conditions? What are the socioeconomic and cultural factors affecting men's role during these conditions?

Much of the interest in increasing male involvement in reproductive health is driven by the premise that such involvement will lead to healthier reproductive health outcomes for men and their partners. In fact, sex education, counselling and health outreach services that have reached men have been shown to promote subsequent reproductive health by delaying the onset of sexual activity and by improving contraceptive efficacy. ${ }^{11,25}$

\section{Methodology}

This study was conducted in Osun State, in the south-west region of Nigeria, between 1998 and 2000. At the time of the survey, Osun State had an estimated population of 2,303,900. Three communities, namely, Ode-Omu, Otan Ayegbaju and Ejigbo were randomly selected. In each of the towns, we selected between 300 and 600 households. Since there was no authentic sample frame (census) at the time of the fieldwork from which study samples could be drawn, we conducted a general household listing in each of the three towns, from which a sample of 300600 households was drawn using a simple random sampling technique. Trained field workers interviewed the husband and wife in each household separately. 
62 African Journal of Reproductive Health

In some households, where there was more than one wife, all the wives along with their husbands were interviewed provided they were within the reproductive age of 15-49 years. In this case, we noted the hierarchy of wives by date and age at marriage to the current husband. Wives who were above age 49 years were excluded from the sample. The implication of this strategy was an over-sampling of the subjects. This worked for the advantage of the survey as we had a large data set that increased the validity, reliability and generalisability of our findings. A total of 1,720 husbands and 1,957 wives were interviewed. The multidisciplinary nature of the study required the expertise of medical sociologists to conduct the qualitative interviews, obstetrician and gynecologist to compile and validate the list of emergency obstetric conditions, demographers to design the survey methodology and supervise the data management.

To complement information collected from the survey, we conducted some sessions of focus group discussion and in-depth interviews. The focus group discussions were conducted among homogenous groups of 8-10 persons with similar socio-economic background. Trained facilitators, assisted by a recorder or note-taker, led the discussions. Sociologists in the research team coordinated the qualitative survey. Six sessions of focus group discussions were organised in each area of study. In all, eighteen sessions were conducted and in-depth interviews were held with some heads of household and their wives. Tapes from the FGDs and in-depth interviews were transcribed by research assistants and entered into the computer. Quantitative analysis was done using STATA (version 7.0). Quantitative analysis was done at three levels, namely, univariate, bivariate and logistic regression (adjusted and unadjusted) with 95\% confidence interval. Results of the quantitative survey were validated with qualitative results.

\section{Profile of Study Subjects}

The mean age of male respondents was 37 years while that of females was 29.1 years. About onethird of the respondents, irrespective of their sex, had secondary education. Majority of the respondents were in monogamous marriage relationships. Many of them had such assets as radio, television, car and motorcycle (data not shown).

Respondents' Knowledge and Attitude to Emergency Obstetric Care and Health-Seeking Practice

Respondents' awareness and attitude to the

Table 1 Percentage Distribution of Respondents' Awareness of Obstetric Conditions by Sex, Osun State, Nigeria

\begin{tabular}{lrr}
\hline Emergency condition & $\begin{array}{c}\text { Male } \\
\text { N=1,720 }\end{array}$ & $\begin{array}{r}\text { Female } \\
\mathbf{N}=\mathbf{1 , 9 5 7}\end{array}$ \\
\hline Percentage aware of labour signs & 53.2 & 89.2 \\
Perception of obstetric conditions as normal & & 15.2 \\
Hypertension & 4.1 & 23.9 \\
Swollen feet & 20.9 & 17.9 \\
Fatigue & 21.9 & 5.4 \\
Abdominal pain without vaginal bleeding & 5.4 & 7.1 \\
Prolonged labour (more than 12 hours) & 1.3 & 3.6 \\
Heavy vaginal bleeding & 0.3 & 7.2 \\
Vaginal bleeding without pains during pregnancy & 4.8 & 5.5 \\
Foul smelling and heavy vaginal discharge post-delivery & 0.8 & \\
\hline
\end{tabular}


concept of emergency obstetric conditions, care and health-seeking role were measured by asking series of questions. A number of obstetric conditions were listed and respondents were asked to comment on their perception of them, including actions they had taken and/or would take in the event of any of such conditions.

Fifty-one obstetric conditions were identified with the assistance of the consultant obstetrician/gynaecologist in the research team. These included hypertension, swollen feet, uterine contraction, prolonged labour (over 12 hours), heavy vaginal bleeding, foul smell after delivery, and heavy bleeding in pregnancy, severe anaemia, among others. The following questions were asked:

(1) How do you regard any of the following cases (list of emergency obstetric conditions): normal, serious, very serious, fatal and don't know?

(2) What was the role of your husband when you had any of the following medical symptoms/conditions?

(3) If a need for the following specific pregnancy conditions arises for you during pregnancy in the absence of your husband, what will you do?

(4) Where would you like to go in the event of any of the conditions?

The same questions were also adapted for male respondents.

Table 1 shows that there was mixed perception by respondents of the normalcy of the emergency conditions, with close to one in every 20 respondents perceiving the emergency obstetric conditions as normal. Majority of the respondents asserted that these conditions are serious, very serious or fatal and require medical attention. Thus, there is high level awareness of the emergency nature of obstetric conditions. More than half of the male respondents expressed awareness of labour signs. Labour signs and usual complaints in pregnancy mentioned by respondents include all sorts of pains, uterine contraction, passage of fluid, tiredness, cold and fever, dizziness, nausea and vomiting, etc. In the focus group discussions, most of the men described the kind of labour signs their wives experienced, an indication that it is not absolutely true that men in a patriarchy society do not know much about pregnancy signs.

\section{Husbands' Role in Health-Seeking Behaviour}

A number of activities have implications for the health of women especially when they are pregnant. Examples are difficult tasks that may affect their health, thereby threatening pregnancy. These include carrying heavy load, bending down a lot, pounding yam or doing any other hard tasks, while positive ones that will be nourishing include eating a lot of food and fruits. We asked the men what would be their attitude if their wives do such things, and asked the women what would be the attitude of their husband if they engaged in such activities. About $12 \%$ of the men would discourage their pregnant wife from engaging in heavy tasks (Table 2). It was also clear that majority of the men would support or encourage their partner to eat fruits and food and do a lot of physical exercises during pregnancy. They believed that this would aid proper fetal and maternal development and health, which is usually recommended at the antenatal clinics.

Close to six out of every ten respondents reported that the men decide on the choice of antenatal care. However, in case of obstetric conditions requiring emergency attention, majority of the respondents $(86.8 \%$ for men and $86 \%$ for women) said that the woman could decide where to go especially in the absence of her husband. The men do not insist that their pregnant wife go to a particular place. This is evidence that the men are informed about the place for antenatal care. The man must however know where his wife goes for medical attention. The finding that a pregnant woman in the study area can decide on where to go during emergency 
64 African Journal of Reproductive Health

Table 2 Respondents' Perception of the Actual Roles of Men in Emergency Conditions

\begin{tabular}{|c|c|c|}
\hline Responses & Male & Female \\
\hline Husband encouraged pregnant wife to do heavy tasks & 12.0 & 20.1 \\
\hline Husband encouraged pregnant wife to do physical exercise & 73.1 & 78.7 \\
\hline Husband encouraged pregnant wife to have good appetite & 90.2 & 74.3 \\
\hline \multicolumn{3}{|l|}{ Family decision-making } \\
\hline Women's antenatal care use & 98.6 & 98.6 \\
\hline \multicolumn{3}{|l|}{ Who decides for place of antenatal care } \\
\hline Husband & 62.3 & 59.2 \\
\hline Wife & 13.0 & 19.6 \\
\hline Both & 23.2 & 18.3 \\
\hline Parents & 0.3 & 1.3 \\
\hline Others & 0.3 & 1.3 \\
\hline \multicolumn{3}{|l|}{ In the absence of partner and emergency condition arises, who decides? } \\
\hline She goes to parents-in-law & 22.7 & 8.7 \\
\hline She decides on her own & 72.4 & 85.5 \\
\hline She has to wait for me & 1.1 & 4.2 \\
\hline She goes to her relations & 2.8 & 1.6 \\
\hline Don't know & 1.1 & - \\
\hline \multicolumn{3}{|l|}{ Specific supports from the husband during pregnancy } \\
\hline Compliance with medication & 46.4 & 40.5 \\
\hline Finance & 95.5 & 90.0 \\
\hline Reminder of clinic days & 52.7 & 45.4 \\
\hline \multicolumn{3}{|l|}{ Husbands who took wife to hospital in selected obstetric emergencies } \\
\hline Hypertension & 92.2 & 97.0 \\
\hline Swollen feet & 92.4 & 92.0 \\
\hline Vaginal bleeding & 95.3 & 93.0 \\
\hline Abdominal pains & 43.1 & 93.0 \\
\hline Prolonged labour & 93.9 & 92.0 \\
\hline Heavy painful discharge & 94.9 & 91.5 \\
\hline Favour caesarean section & 87.2 & 70.3 \\
\hline \multicolumn{3}{|l|}{ What to do in obstetric emergency when the husband is available } \\
\hline Go to my parents-in-law & 5.5 & 8.7 \\
\hline Will wait for him & 1.2 & 4.2 \\
\hline Will decide on my own & 86.8 & 85.5 \\
\hline I will go to relations & 1.2 & 1.6 \\
\hline \multicolumn{3}{|l|}{ What action to take in case of the following emergency conditions } \\
\hline Hypertension & 89.8 & 81.7 \\
\hline Swollen feet & 87.1 & 81.6 \\
\hline Uterine contraction & 89.2 & 75.7 \\
\hline Vaginal bleeding & 90.6 & 80.9 \\
\hline
\end{tabular}

contradicts the belief that in most patriarchal societies women seek the permission of a male head of the household before attending antenatal clinic or that she must be escorted by a male member of the household to a health facility. ${ }^{26}$ Only $4 \%$ of the women said they would wait for their partner to come back before taking any decision, while an insignificant $1 \%$ of the men said that the women should wait for them.

The male respondents reported giving the following support to their wife when they were 
Men's Role in Emergency Obstetric Care in Osun State of Nigeria

pregnant: financial support (96\%), compliance with medical prescription (46\%), and remind her of clinic days (53\%). Financial support was the most popular.

The perceived roles identified by women as ideal for husbands in maintaining the general wellbeing of their wives differed slightly between the sexes. Female respondents felt that husbands' ideal roles toward women's health should include taking wife to hospital for treatment, providing money, ensuring good health, showing affection, and ensuring compliance with medication. For the men, their ideal roles include taking wife to hospital for treatment, helping in household chores, provision of financial support, ensuring compliance with medication, providing food, clothing and shelter, showing affection to wife, monitoring wife's clinic attendance, and ensuring emotional stability of wife.

The busband should take the pregnant wife to the hospital for registration, provide funds for hospital bills and check the condition of the woman's health. .. (Male, IDI)

Some of the negative roles husbands play in their wife's health status include neglect of responsibilities, failure to pay hospital bills, inability to follow wife to the clinic and general neglect. Commenting on the negative role of men towards their pregnant wife, a female opinion leader said:

Men in this area see their wives as filthy rags.

Their only hope and joy with them is sexual relationship. Once the wives are pregnant, they desert them till when they need sex.

This may be an extreme view.

Men in a focus group discussion responded as follows:

Some men in this place show love to their wives only when they want to have sex. What happens later to the woman is none of their business.
Most of the time they quarrel over sex matters, especially during pregnancy. What they do is to hate such wives and refuse to care for them even in pregnancy. Many of our men desire 'children only' from their wives, they do not care to have any responsibility over them and their children (FGD with $<45$ year old men).

In a focus group discussion session with women aged 15-34 years, respondents agreed:

The first thing a caring husband does is to take his wife to the hospital or maternity home for registration for scheduled clinical visits as soon as pregnancy occurs. He must monitor the regular visits of his wife to the hospital from the time the pregnancy occurs till the time of delivery. He must provide sufficient funds to cover all the bills incurred in the hospital.

\section{Men's Knowledge about Pregnancy and Related Risks}

Participants in the focus group discussions and in-depth interviews agreed that men's knowledge of pregnancy is inadequate.

What we know about pregnancy is grossly inadequate. Parents do not teach their children about pregnancy and its outcomes. Pregnancy here is shrouded in secrecy. This contributes to our lack of knowledge. (FGD, Men aged $45+)$

A male opinion leader in an informant interview said:

The current hospital programme for pregnancy concentrates on women without reference to men. If men are seen as agents of change and for improved pregnancy outcomes, they would have no choice but show commitment.

There was no much difference between 
66 African Journal of Reproductive Health

women's expectations of their husband and what the men actually did during emergency obstetric conditions (data not shown).

Further disaggregation of the relevant responses by two major socio-economic factors, namely, age and level of education, highlights the significant contribution of these two variables to respondents' perceptions, attitudes and specific actions taken during emergency obstetric conditions. For instance, those who reported that emergency obstetric conditions were normal, serious, very serious or fatal varied by age and educational level. More of the older men and women than the younger respondents aged 1534 years perceived these as normal. This was the same for the level of education; those with low level of education saw the conditions as normal, like those with high level of education (data not shown).

However, in terms of specific action taken when the woman experienced the condition, onethird of the younger and older men took their wives to the hospital for treatment while more of the educated men (that is, those with secondary education and above) took their wives to the hospital than those with lower level of education. There was not much variation in husbands' attitude to specific activities that their wives perform when they were pregnant; more than eight out of every ten respondents, irrespective of age and level of education, discouraged their wives from performing heavy tasks such as carrying loads, bending down, drawing water from the well, pounding yam, washing floors and other hard tasks.

Though there was a common agreement in this study that men are the major decision-makers, there was evidence that when it involves danger and in the absence of the main decision-maker, the woman is at liberty to take any decision that will save her life and the pregnancy. Controlling for age and education, there was not much difference; the younger and older, low and highly educated men and women were in agreement. There was no socio-economic differential in survival instincts in men, as everybody would like to live. As regards the choice of place of treatment in case of obstetric emergencies, there was general preference for government hospital (teaching and general hospitals) and private hospitals. The seriousness of these conditions demands that experts commonly seen at the teaching hospital, rather than the private health centres, attend to them. However, casual discussions with interview respondents and focus group discussants revealed their patronage of traditional medicine and traditional health-care delivery in emergency obstetric conditions, especially when finance is insufficient and where modern facilities are inaccessible, either because of bad road network, lack of transportation, or outright lack of facilities in modern health-care delivery points.

\section{Correlates of Men's Knowledge of, and Role in Emergency Obstetric Conditions of their Spouses}

Table 3 shows factors predicting the likelihood that male respondents were aware of pregnancy signs and labour symptoms. Knowledge of pregnancy and labour signs varied significantly by age and level of education when adjusted and unadjusted, an indication of their power of influence. The older and educated men were more likely to be aware of these signs than the younger and uneducated ones. Those who belonged to the Islamic religion were 57\% less likely to demonstrate any knowledge of emergency obstetric condition. Also, knowledge of emergency conditions increased with the number of wives a man had. The man had acquired experiences from the first wife and may have had a number of life experiences that ought to affect his knowledge. Availability of health facilities was another significant factor. Media exposure was only significant when adjusted with other variables.

Majority of the men permitted their wives to decide on their health-care in the absence of the husband. The age of respondents, educational

African Journal of Reproductive Health Vol. 9 No.3 December 2005 
Table 3 Adjusted and Unadjusted Logistic Odds Ratio of Factors Predicting Men's Knowledge of and Role in Emergency Obstetric Conditions

\begin{tabular}{|c|c|c|c|c|c|c|}
\hline \multirow[t]{2}{*}{ Characteristic } & \multicolumn{3}{|c|}{ Unadjusted odds ratio } & \multicolumn{3}{|c|}{ Adjusted odds ratio } \\
\hline & OR & $95 \% \mathrm{CI}$ & p value & OR & $95 \% \mathrm{CI}$ & p value \\
\hline Age squared & 1.00 & $1.0-1.0$ & 0.000 & 1.00 & $1.0-1.0$ & 0.000 \\
\hline \multicolumn{7}{|l|}{ Education } \\
\hline$\leq$ Primary & 1.59 & $1.13-2.20$ & 0.008 & 1.52 & $1.00-2.20$ & 0.025 \\
\hline Secondary and above & 1.70 & $1.1-2.70$ & 0.010 & 1.73 & $1.10-2.80$ & 0.030 \\
\hline \multicolumn{7}{|l|}{ Religious affiliation } \\
\hline Protestant & 0.60 & $0.37-0.98$ & 0.040 & 0.68 & $0.40-1.20$ & Ns \\
\hline Pentecostal & 0.87 & $0.47-1.61$ & $\mathrm{~ns}$ & 1.00 & $0.51-1.95$ & Ns \\
\hline Islam & 0.57 & $0.37-0.88$ & 0.010 & 0.79 & $0.49-1.27$ & Ns \\
\hline \multicolumn{7}{|l|}{ Number of wives } \\
\hline$>2$ & 1.70 & $1.20-2.50$ & 0.004 & 1.80 & $1.13-2.90$ & 0.013 \\
\hline Availability of health facility & 2.06 & $1.50-2.80$ & 0.000 & 1.70 & $1.11-2.60$ & 0.015 \\
\hline \multicolumn{7}{|l|}{ Media exposure } \\
\hline Radio & 0.93 & $0.56-1.56$ & ns & 0.95 & $0.48-1.89$ & Ns \\
\hline Television & 1.27 & $0.94-1.72$ & ns & 1.61 & $1.03-2.50$ & 0.033 \\
\hline
\end{tabular}

The reference categories are the missing categories of each of the variables

ns $=$ not significant at the 95\% confidence interval

Table 4 Adjusted and Unadjusted Logistic Odds Ratio of Factors Predicting Men's Role in Emergency Obstetric Conditions

\begin{tabular}{|c|c|c|c|c|c|c|}
\hline \multirow[t]{2}{*}{ Characteristic } & \multicolumn{3}{|c|}{ Unadjusted odds ratio } & \multicolumn{3}{|c|}{ Adjusted odds ratio } \\
\hline & OR & $95 \% \mathrm{CI}$ & p value & OR & $95 \% \mathrm{CI}$ & p value \\
\hline Age squared & 1.0 & $0.99-1.0$ & 0.05 & 1.0 & Ns & \\
\hline \multicolumn{7}{|l|}{ Education } \\
\hline$\leq$ Primary & 2.02 & $1.21-3.40$ & 0.007 & 1.38 & & $\mathrm{Ns}$ \\
\hline Secondary and above & 2.38 & $1.10-5.10$ & 0.024 & 0.82 & & $\mathrm{Ns}$ \\
\hline Availability of health facility & 2.40 & $1.50-3.90$ & 0.001 & 2.60 & $1.16-5.90$ & 0.020 \\
\hline \multicolumn{7}{|l|}{ Media exposure } \\
\hline Radio & 2.09 & $1.03-4.20$ & 0.041 & 1.74 & & Ns \\
\hline Television & 1.1 & $0.69-1.80$ & ns & 0.95 & & $\mathrm{Ns}$ \\
\hline \multicolumn{7}{|l|}{ Asset ownership } \\
\hline Television & 5.88 & $2.03-17.0$ & 0.001 & 3.19 & & Ns \\
\hline Refrigerator & 7.75 & $2.70-22.2$ & 0.000 & 4.14 & & Ns \\
\hline \multicolumn{7}{|c|}{ Perception of emergency obstetric conditions } \\
\hline Serious & 2.2 & $0.82-5.65$ & ns & 1.96 & & Ns \\
\hline Very serious & 1.08 & $0.41-2.78$ & ns & 1.19 & & Ns \\
\hline Fatal & 7.11 & $1.34-37.5$ & 0.021 & 7.84 & & Ns \\
\hline
\end{tabular}

The reference categories are the missing categories of each of the variables.

$n s=$ not significant at the $95 \%$ confidence interval

African Journal of Reproductive Health Vol. 9 No.3 December 2005 
68 African Journal of Reproductive Health

level, media exposure, availability of health facility, asset ownership and perception of emergency obstetric conditions as fatal were significant factors affecting the likelihood that the man would support the spouse to decide on her health-care in emergency conditions. These factors were significant individually. When adjusted with other factors, their significance disappeared, although positive relationship with the dependent variable was in the expected direction (Table 4).

\section{Discussion and Implications}

This study set out to examine the practical implications of male gender role supremacy in emergency obstetrics. A survey in northern Nigeria reported that women do not go to health clinics unless with the permission of their husbands. This finding has been over-flogged, as no recent empirical case study has demonstrated the continued existence of such culture. It could have been in existence, but with the changing nature of society, change could have taken place while researchers kept emphasising an outdated cultural practice. The findings of this study tend to support this view.

There was high level awareness of the signs and symptoms of pregnancy and labour by the men. An examination of the list of 51 symptoms of emergency obstetric conditions shows that majority of the men (on the average eight out of ten) perceived these signs as abnormal and should be taken to the hospital for medical attention. This study shows rather that men play important roles in emergency obstetric condition of their partners. They take their pregnant wives to the hospital when there is an emergency and make financial contribution for health bills. Payment of antenatal health bill is a cultural responsibility of the husband. Irrespective of the status of the woman, it is the responsibility of the man to take his pregnant wife to the clinic. A man who is not able to pay for his wife's hospital bills is looked at with disdain in the community and is regarded as an irresponsible man.
This study does not reveal any significant practice of male gender supremacy in women's health-care issues as often cited in the literature. That men are the major decision-makers in the study does not imply the concept of 'supremacy'. What the men do is to assist in taking decision and making choices of where the pregnant woman should go for antenatal care. It is not a gender issue for a man to decide that the wife should go for antenatal clinic in any health centre or hospital, but a matter of economics. This choice is a factor of the economic and social situation of the family. A poor family that is living in the rural area should not expect to be attending a first-class hospital for antenatal care. Definitely, in seeking the opinion of the husband, he will settle for a cheaper and closer care centre. The husband makes sure that his wife is fully booked. The husband decides based on his financial capability, and where there is need for expert advice, he obliges depending on his financial power.

Even if the men decide where to go for antenatal care and delivery, it is interesting to note that the same men would allow their wives to take decision on their health in their absence. Using the decision-making role of the husband as an index of male supremacy or dominance is faulty. The men are the main decision-makers in the next child and place of antenatal care decisions, yet they allow their spouses to take critical decisions in their (men's) absence, especially when it involves their health. Most of the actions attributed to African men may be due to poverty and ignorance. For instance, a man may stop his pregnant wife from registering in a tertiary health institution as a result of poverty rather than for reasons of masculinity.

These findings could be due to the interplay of a number of factors in the area, such as the socio-economic level of the respondents and the area of study, media exposure, and the role of non-governmental organisations. Our bivariate and logistic analyses further showed significant effect of age and education on men's knowledge

African Journal of Reproductive Health Vol. 9 No.3 December 2005 
of and attitude to emergency obstetric conditions and health-seeking behaviour. The two variables consistently affect the respondents' perception and attitudes towards emergency obstetric care choices and decisions.

These findings are not surprising because the area of study is one of the most enlightened states in Nigeria, with three universities and many other tertiary institutions. There are two teaching hospitals, more than five general hospitals and numerous health centres. Free universal basic education has been the hallmark of the area since 1955. The Yoruba, who are the residents of the area studied, are the most educated in Nigeria, hence the understandable impact of education on male involvement in emergency care.

The role of non-governmental organisations in this change in male behaviour cannot be overruled. The largest concentration of activist non-governmental organisations in reproductive health is in the region. They have been involved in a number of community outreaches and mobilisation programmes for the promotion of male involvement in reproductive health. This may be one of the outcomes of these efforts. Media exposure could be another reason. The state radio station usually broadcasts health information, which must have influenced the thinking of the men and their involvement in their spouse's health. Another contributory factor to the patterns observed in this study could be the high level of antenatal clinic attendance, as more than $80 \%$ of pregnant women in the area attended antenatal clinics. High utilisation of health facilities improves knowledge of obstetric conditions, which is usually transferred to men either through their wives, media talks or at community meetings.

There is clear evidence of social change in Nigeria, at least in the south-west region where this study was conducted. Men are getting involved in the reproductive health of their partners. For this involvement to permeate every segment of the Nigerian society is another challenge for policymakers and programmers. While the study shows that men are getting involved in the health-care of their wives, there is still need for sustained campaigns to improve the health of women in the area. One best approach is to promote education for men and women at all levels. This is one sure way the ideals of ICPD and Beijing can be realised. Education is paramount. It can make the difference, as was observed in this study. The young men also need to be targeted, because it is easier to change their attitudes and perceptions when they are still young.

\section{Limitations}

There are methodological issues in this study. The methodology of identifying men's attitudes towards their wives should be sharpened so that attitudes of polygnously married men to their different wives could be captured under different living arrangements. Secondly, our approach in the design of the instrument of the study could not allow for rigorous statistical analysis. The list of obstetric conditions is too lengthy to have been meticulously administered by the field workers. Questions on specific experiences of these conditions were not asked. A prospective research design would be a good option to collect dynamic information on male roles in emergency obstetric conditions. Pregnant women and their partners should be targeted and monitored over a period of time. This study reveals that there is social change in the concept and practice of male supremacy in Nigeria. Further studies are required in other regions in the country and elsewhere to measure the extent of male awareness and involvement in the reproductive health conditions of women. The overall problem of high maternal mortality could be solved with strong political will, education and massive health infrastructural development.

\section{Acknowledgements}


70 African Journal of Reproductive Health

We are grateful to the John $\mathrm{D}$. and Catherine T. MacArthur Foundation, Chicago, USA for sponsoring the survey under Grant Number 41863. The role of the entire staff of the Centre for Research, Evaluation Resources and Development, Ede, Osun State, Nigeria, in the implementation of the project is deeply appreciated, and to the Management of Takemi Program in International Health for logistic support to the first author to do the analysis, we are grateful. This paper was written while the first author was a Takemi Fellow at the Harvard University, Cambridge, Mass, USA.

\section{REFERENCES}

1. UNFPA. The State of the World Population. New York, 2001.

2. Harrison KA and John CT. Maternal mortality in developing countries. Lancet 1996; 347(8998): 400.

3. Maine D. Studying maternal morbidity in developing countries: rates and causes: a g u id e b o o k. W H O / F H E / 8 7 . 7 . Unpublished, 1987.

4. Main D. Safe Motherhood Programs: Options and Issues. New York: Columbia University Center for Population and Family Health, 1987.

5. Rosenfield A and Maine D. Maternal health in third world. Lancet 1987; 1(8534): 691.

6. Royston E and Armstrong S. Preventing Maternal Deaths. Geneva: WHO, 1989; 233p.

7. Durfee RB. Obstetric complications or pregnancy. In: ML Pernell and RC Benson (Eds.). Current Obstetrics and Gynecologic Diagnosis and Treatment. Connecticut: Appleton and Large, 1987; 255pp.

8. Adewuyi AA. Pregnancy Care: Understanding Male Involvement in Maternal Emergencies. Nigeria: CRERD, 1999.

9. Obermeyer CM. Culture, maternal health care and women's status: a comparison of Morocco and Tunisia. Stud Fam Plann 1993;
24(6): 354-365.

10. United Nations. Program of Action: International Conference on Population and Development. Cairo: United Nations, 1994.

11. Ezeh Alex C. The influence of Spouses over each other's contraceptive attitudes in Ghana. Stud Fam Plann 1993; 24(3): 163-174.

12. Feyisetan BJ, K Oyediran and $G$ Ishola. Role of Men in Family Planning in Imo State, Nigeria. Nigeria: NISER, 1998; 1-64.

13. Murphy M and Baba TM. Rural dwellers and health care in Northern Nigeria.Soc Sci Med 1981; 15A(3/1): 265-271.

14. Stock R. Distance and utilization of health facilities in rural Nigeria. Soc Sci Med 1983; 17(9): 563-570.

15. Robey B, Rutstein SO, Morris L and Blackburn R. The reproductive revolution: new survey findings. Pop Reports 1992; Series $M$, No. 11.

16. Lauman EO, Gagnon GH, Michael RT and Michaels S. The Social Organization of Sexuality: Sexual Practices in the United States. Chicago: University of Chicago Press, 1994.

17. Odebiyi AI and Ondolo O. Female involvement in intervention programs: the EPI experience in Saradidi, Kenya. E Afr Med J 1993; 70(1): 25?33.

18. Orubuloye IO. Male Sexual Behavior and Its Cultural, Social and Attitudinal Context: Report on a Pilot Survey in a Nigerian Urban Population. Health Transition Center, Australian National University, 1994.

19. De Zalduindo BO, Msamanga GI and Lincoln Chen. AIDS in Africa: diversity in the global pandemic. Daedalus 1989; 118(3): 165-204.

20. Adamchak Donald and Akin Adebayo. Male fertility attitudes: a neglected dimension in Nigeria fertility research. Social Biology 1987; 34(1): 57-67.

21. Karanja Wambui Wa. "Outside wives" and "inside wives" in Nigeria: a study of chang-

African Journal of Reproductive Health Vol. 9 No.3 December 2005 
ing perceptions in marriage. In: David Parkin and David Nyamwaya (Ed.). Transformation of African Marriages. Manchester: Manchester University Press, 1987.

22. Afonja Simi. Women, power and authority in traditional Yoruba society. In: L Dube, E Leacock and S Ardener (Eds.). Visibility and Power. South Hadley: Bergin and Garvey, 1996; 136-157.

23. Renne Elisha P. Gender ideology and fertility strategies in an Ekiti Yoruba village. Stud Fam Plann 1993; 24(6): 343-353.

24. Ware Helen. Female and male life cycles. In: C Oppong (Ed.). Female and Male in West
Africa. London: Allen and Unwin, 1983.

25. Desai S. The Influence of Family Structure on Child Welfare in Latin America and West Africa: Understanding how Resources are Allocated within Households. New York: World Bank, 1992.

26. Castle S. Intra-household differentials in women's status: household functions and focus as determinants of children's illness management and care in rural Mali. Health Trans Rev 1993; 3(2): 137-158.

27. National Population Commission (Nigeria). Nigeria Demographic and Health Surveys 1999. Calverton: National Population Commission and ORC/Macro, 2000. 